\title{
pH Response of Colored Copolypeptide Hydrogel Containing Tryptophan Treated with Nitric Acid
}

\author{
Hideki Sugimoto, Eiji NaKanishi, ${ }^{\dagger}$ Katsuo Susaki, \\ and Sadao HiBI
}

Department of Materials Science \& Engineering, Nagoya Institute of Technology, Gokiso-cho, Showa-ku, Nagoya 466-8555, Japan

(Received November 17, 1997)

\begin{abstract}
Coloration of L-tryptophan (Trp) treated with nitric acid was observed under varying $\mathrm{pH}$, i.e., between yellow (below pH 10.5) and red (above $\mathrm{pH}$ 12.5). To elucidate the coloration mechanism of Trp by treatment with nitric acid, the colored compound was fractionated and investigated spectroscopically. Trp formed a yellow compound consisting of a tricyclic structure, and nitro groups were introduced into the indole ring. The color change with the variation of $\mathrm{pH}$ is due to the dissociation of nitrogen atoms in the indole ring. Colored copolypeptide hydrogel containing Trp residues was also prepared by aminolysis of copoly $(\gamma$-benzyl L-glutamate-co-Trp) membrane in the presence of crosslinking agent and by immersion of the membrane in nitric acid. Color change was also observed for the hydrogel. The $\mathrm{pH}$ dependence of such membrane properties as degree of swelling and permeability coefficient of styrene glycol was investigated. These properties changed drastically in the $\mathrm{pH}$ region of color change. This can be explained by the dissociation of Trp residues.

KEY WORDS Tryptophan / Color Change / Copolypeptide Hydrogel / Treatment with Nitric Acid / pH Response /
\end{abstract}

Poly( $N$-hydroxyalkyl L-glutamine), in hydrogels or vital tissue, features a peptide bond and is expected to be applicable to biomaterial production due to its flexibility, inactivation of antigen-antibody reaction, ${ }^{1}$ biodegradability, ${ }^{2-6}$ non-toxicity of degradation products, ${ }^{7}$ and so on..$^{8-12}$ We previously reported that conformations of peptide chains in hydrogels can be controlled and membrane properties, such as degree of swelling, solute permeability, enzymatic degradability, and mechanical properties, can be regulated by altering the hydrophobicity of the side chains. ${ }^{13-15}$ This paper reports polypeptide hydrogels containing L-tryptophan (Trp) residues, which contain an indole ring and have the largest hydrophobicity among natural amino acids. Trp is oxidized easily under an acidic condition and changes into various structures due to the high electronic density of the indole ring. For example, when the pyrindole compound is brought into contact with sulfuric acid and a trace of oxidizing agent is added, blue color develops which slowly is transformed to dirty green and finally a yellow, ${ }^{16}$ and perchloric acid converts Trp to a greenish-yellow compound and subsequent addition of iron chloride changes the greenish-yellow Trp to a reddish-orange color. ${ }^{17}$ This method is used for detection of Trp within proteins. Trp also shows coloration by condensation reaction between the carbonyl group of various aldehyde compounds and a carbon atom at the 2-position of the indole ring under acidic conditions. This reaction can be classified as Hopkins-Cole (fatty aldehyde) or Neuberger-Rhode reaction (aromatic aldehyde). The products show various colors, and the structure of each has been clarified. These procedures are used in qualitative and quantitative analysis of peptides including Trp. Since pink colored by-products were produced by the accidental oxidation of the indole ring of Trp during peptide synthesis, attempts have been

\footnotetext{
† To whom correspondence should be addressed.
}

made to depress these formations. ${ }^{18,19}$ With the exception of a report on the reaction of Trp and aldehyde, no reports have been made on the coloration of Trp.

We previously found that Trp is colored when treated with strong acids, such as nitric acid, trifluoroacetic acid (TFA) or dichloroacetic acid (DCA), and shows reversible color change with variation of $\mathrm{pH} .{ }^{20} \operatorname{Trp}$ treated with TFA forms a tricyclic structure and shows color change from red (below pH 4.0) to yellow (above $\mathrm{pH}$ 5.5) by the dissociation of indole ring. ${ }^{21}$ Trp treated with nitric acid showed opposite color change against $\mathrm{pH}$, that is, from yellow (in acidic $\mathrm{pH}$ ) to red (in alkaline $\mathrm{pH}$ ). The present study clarifies the coloration mechanism of Trp by treatment with nitric acid. First, $N$-acetyl Trp ethyl ester (ATE) was treated with nitric acid. The compound having the target color was fractionated by column chromatography, and its structure was investigated by spectroscopic measurements. Structural change accompanied by color change with the variation of $\mathrm{pH}$ was also proposed. A colored copolypeptide hydrogel including Trp residues was prepared by treatment with nitric acid, and the $\mathrm{pH}$ dependence of physical properties of the membrane was investigated.

\section{EXPERIMENTAL}

\section{Materials}

Preparation and Purification of $\mathrm{N}$-acetyl Trp Ethyl Ester Treated with Nitric Acid. ATE was dissolved in nitric acid with irradiating ultra violet (UV) (wavelength $365 \mathrm{~nm}$, intensity $300 \mu \mathrm{w} \mathrm{cm}^{-2}$ ) for $72 \mathrm{~h}$. Crude ATE treated with nitric acid (ATE-N) that shows reversible color change with variation of $\mathrm{pH}$ was obtained by adding $n$-hexane and diethyl ether to acid solution. ATE-N was purified by column chromatography using ODS gel (Fuji Silisia Chromatrex DM1020T, 100-200 mesh) as packing to obtain the compound with the target color. The purity of ATE-N after purification was 
checked by HPLC (TOSOH CCPE, UV-8000, ODS$80 \mathrm{TM})$ using methanol-water $(2: 1, \mathrm{v} / \mathrm{v})$ as developing solvent, and peak detection was carried out at $254 \mathrm{~nm}$.

\section{Synthesis of Random Copolymer}

The starting copolymer (GT) consisting of $\gamma$-benzyl L-glutamate ( $\gamma$-BLG) and Trp was synthesized using $N$-carboxyanhydride (NCA) method. $\gamma$-BLG NCA and Trp NCA were prepared by reaction with bis(trichloromethyl) carbonate (triphosgene), ${ }^{2-24}$ and purified by recrystallization from ethyl acetate solution with petroleum ether. These $\gamma$-BLG NCA and Trp NCA, at a mole ratio of 9 to 1 , were dissolved in a $1: 1(\mathrm{v} / \mathrm{v})$ mixture of dioxane and dichloromethane. Polymerization was initiated with triethylamine (TEA) at an NCA-to-TEA molar ratio of 50 to 1 . The starting copolymer was precipitated in a large amount of cold methanol and dried in vacuo. All solvents used were distilled twice. The composition of GT was estimated by ${ }^{1} \mathrm{H}$ NMR measurement and elementary analysis.

\section{Preparation of the Hydrophilic Membrane}

The hydrophilic copolymer membrane, poly $(N$-hydroxyethyl L-glutamine-co-Trp) (EGT), was prepared by aminolysis of GT membrane cast from chloroform solution. ${ }^{25}$ GT membrane was immersed in 2-amino-1ethanol (EA) with $10 \mathrm{~mol} \%$ of crosslinking agent, 1,8octamethylenediamine (OMDA), at $58^{\circ} \mathrm{C}$ for $72 \mathrm{~h}$. Debenzylation of GT was confirmed by the disappearance of absorption due to ester groups at $1740 \mathrm{~cm}^{-1}$ in IR spectrum. Figure 1 presents a schematic diagram of the preparation of EGT membrane. Linear water soluble copolymer without crosslinking was also prepared according to the same method as for the hydrophilic membrane. The water soluble copolymer was obtained by dialysis and lyophilized.

\section{Preparation of Colored Membrane}

Yellow-colored, nitric acid-treated membrane, EGT$\mathrm{N}$, was prepared by a method similar to that for ATE. The treatment of the membrane with nitric acid was carried out for $1 \mathrm{~h}$ to prevent degradation of the main chain. The EGT-N membrane was washed repeatedly with methanol and water to remove remaining nitric acid and dried in vacuo for $72 \mathrm{~h}$.

\section{Measurements}

Methods. The structure of purified ATE-N was estimated by ${ }^{1} \mathrm{H}$ NMR (Varian Associates Model XL-200 spectrometer) and IR (Shimadzu Model FT-IR 4200 spectrophotometer) measurements. Chemical shifts in ${ }^{1} \mathrm{H}$ NMR spectra are reported as $\delta$ values (ppm) relative to tetramethylsilane (TMS) as the internal standard. IR spectra were measured by $\mathrm{KBr}$ in the region of 4000 $400 \mathrm{~cm}^{-1}$. UV-VIS absorption spectra of EGT-N membrane and ATE-N were measured by a JASCO Model V-520 spectrophotometer with a quartz cell having a path length of $1 \mathrm{~cm}$. pH was adjusted by $5 \mathrm{~N}$ $\mathrm{NaOH}$ and $\mathrm{HCl}$ to control the change of concentration at a minimum. Nonaqueous titration with thymol blue (TB) as an indicator was carried out to elucidate the existence of negatively charged ATE-N. Titration was performed by dissolving ATE-N in dimethylfor-

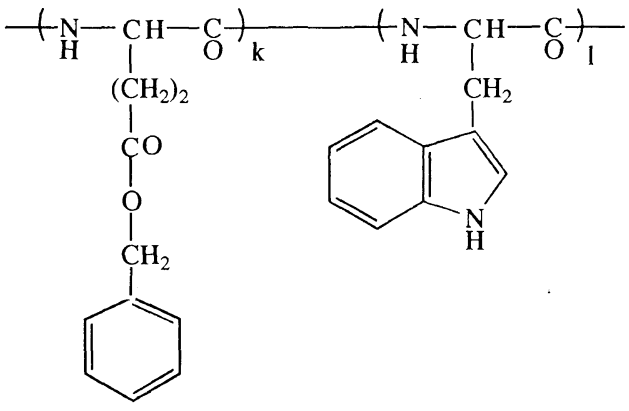

GT Film

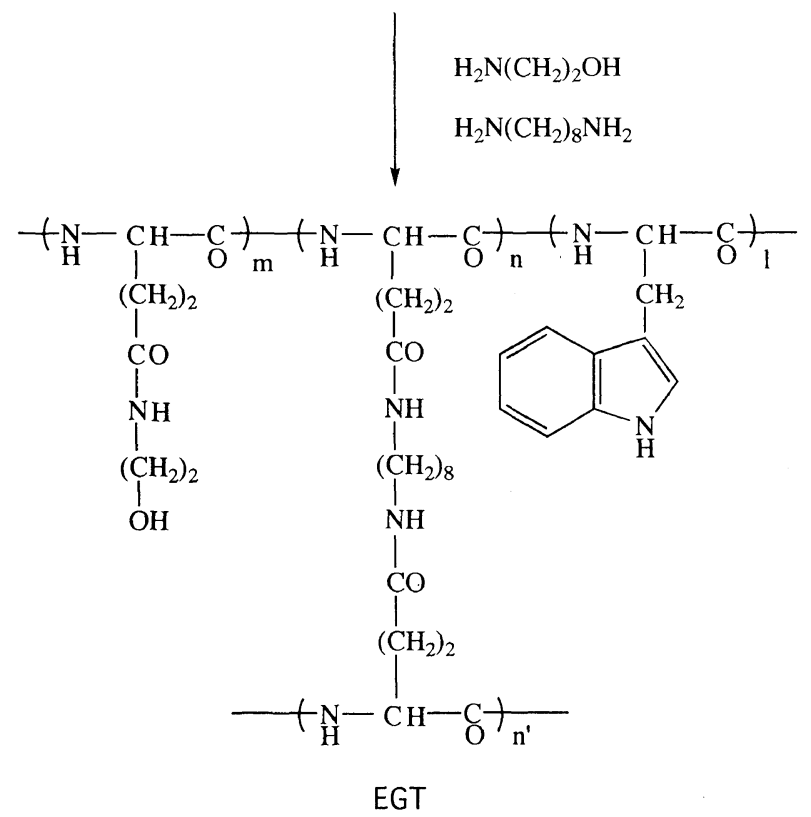

Figure 1. Schematic diagram of the preparation of the EGT membrane.

mamide (DMF) and then $0.1 N$ sodium methoxid/benzene solution added dropwise to the ATE-N solution in an atmosphere of nitrogen. The end point of TB was taken as the point where the color of the solution changed from pale yellow to blue.

\section{Degree of Swelling of the EGT-N Membrane}

The degree of swelling $Q_{\mathrm{w}}(\%)$ was determined by equilibrating the membrane in various buffer solutions at $25^{\circ} \mathrm{C} . Q_{\mathrm{w}}$ is given by,

$$
Q_{\mathrm{w}}=\frac{W_{\mathrm{w}}-W_{\mathrm{d}}}{W_{\mathrm{d}}} \times 100
$$

where $W_{\mathrm{w}}$ and $W_{\mathrm{d}}$ are the weight of the hydrogel and xerogel, respectively.

\section{Solute Permeability of the EGT-N Membrane}

To examine the $\mathrm{pH}$ dependence of solute permeability of EGT-N membrane, solute permeation of styrene glycol throughout the membrane was measured with membrane-separated glass cells at $25^{\circ} \mathrm{C}$. The permeability coefficient $\left(P_{\mathrm{s}}\right)$ is given by,

$$
J_{\mathrm{s}}=\frac{\mathrm{d} C_{0}}{\mathrm{~d} t} \times \frac{V}{S} \quad P_{\mathrm{s}}=\frac{J_{\mathrm{s}} \times \Delta x}{\Delta c}
$$

where $J_{\mathrm{s}}$ is the flow rate, $\mathrm{d} C_{0} / \mathrm{d} t$ is the increment rate of 

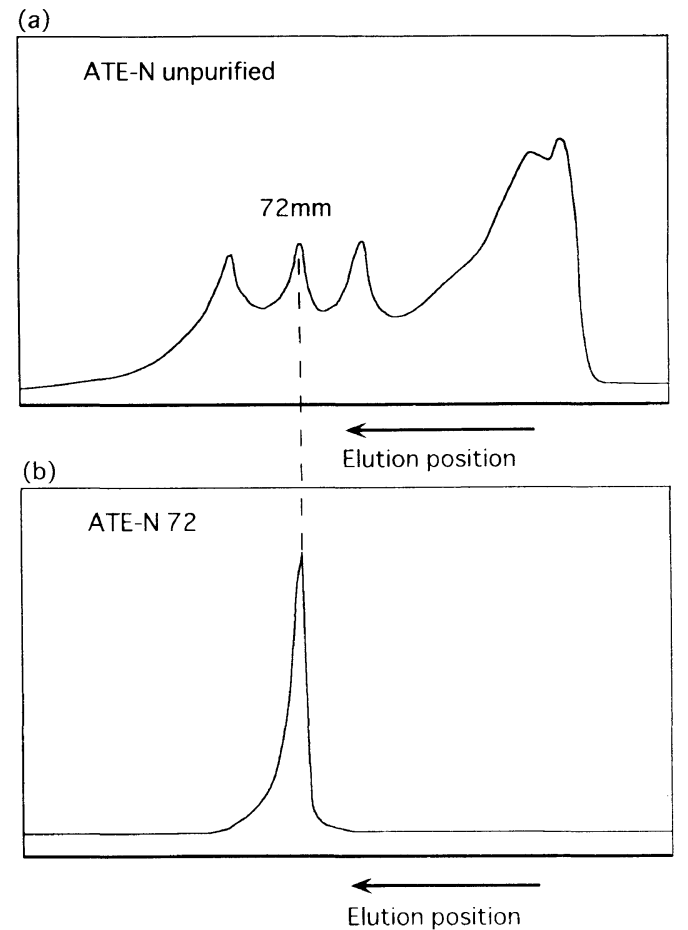

Figure 2. Results of HPLC before and after purification: (a) ATE-N unpurified and (b) ATE-N 72.

solute concentration in the side having lower concentration, $V$ is the volume of the lower concentration side, $S$ is the effective permeation area, $P_{\mathrm{s}}$ is the permeability coefficient, $\Delta x$ is the thickness of the swelled membrane and $\Delta c$ is the difference of initial concentration. The increment rate of styrene glycol was estimated from the absorption intensity at $256 \mathrm{~nm}$ in UV measurement. Initial concentration in the higher concentration side was $2.5 \times 10^{-2} \mathrm{moll}^{-1}$.

\section{RESULTS AND DISCUSSION}

\section{Color Change of ATE-N}

The solution of ATE-N was colored yellow below $\mathrm{pH}$ 10.5 to absorb the wavelength (around $400 \mathrm{~nm}$ ) that appears bluish-purple to purple, and became red as it absorbed the wavelength (around $500 \mathrm{~nm}$ ) that appears as blue above $\mathrm{pH}$ 12.5. ATE-N exhibits absorption around $370 \mathrm{~nm}$ in UV spectrum. Many aromatic nitro compounds, such as dinitro aniline and nitro aniline, show yellow color to absorb the light around $300 \mathrm{~nm}$ to $400 \mathrm{~nm} .{ }^{26}$ From these results, we conclude that ATE-N shows reversible color change in the $\mathrm{pH}$ region of 10.5 to 12.5 and nitro group is apparently introdued into the indole ring when treated with nitric acid.

\section{Color Change of Purified ATE-N}

Figure 2 shows the results of HPLC of ATE-N before and after purification measured using a methanol-water $(2: 1, \mathrm{v} / \mathrm{v})$ mixture as developing solvent. ATE-N indicates four peaks at $20-30 \mathrm{~mm}$, at $62 \mathrm{~mm}$, at $72 \mathrm{~mm}$, and at $84 \mathrm{~mm}$, respectively. By the area summation method, ATE-N consists of $13 \%$ of the compound that shows a peak at $62 \mathrm{~mm}, 14 \%$ of the compound that shows a peak at $72 \mathrm{~mm}$, and $16 \%$ of the compound that shows a peak at $84 \mathrm{~mm}$. From the results of HPLC after

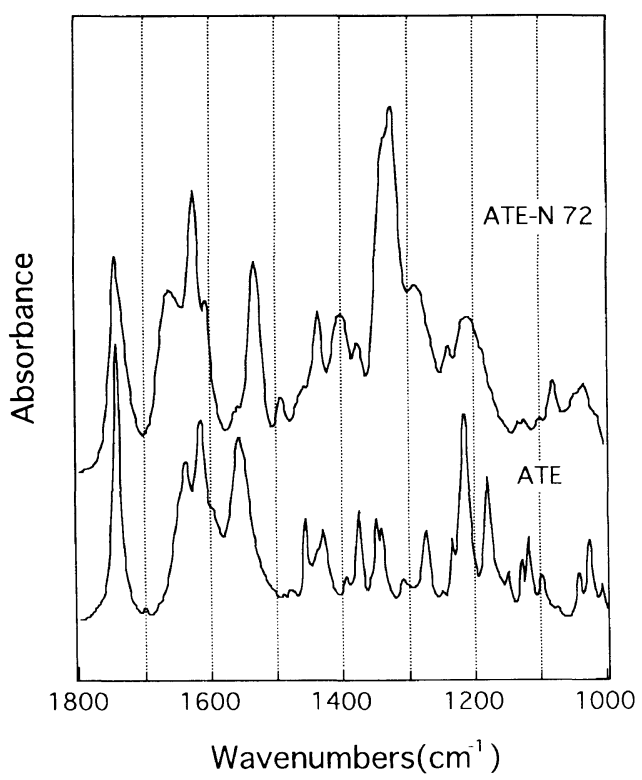

Figure 3. IR spectra of ATE and ATE-N 72.

purification, the compounds that show a peak at $72 \mathrm{~mm}$ (ATE-N 72) could be separated.

ATE-N 72 shows reversible color change as well as unpurified ATE-N in the $\mathrm{pH}$ region of $\mathrm{pH} 10.5$ to 12.5 . Both compounds that showed the peaks at $62 \mathrm{~mm}$ and at $84 \mathrm{~mm}$ also change in color between yellow and red in the same $\mathrm{pH}$ region, though these compounds could not be separated completely. This suggests that ATE$\mathrm{N}$ consists of several components that have similar structure. The other peaks could not be separated since they were in close proximity.

\section{Estimation of Structure of ATE-N 72}

Figure 3 illustrates IR spectra of ATE and ATE-N 72. By comparison of their IR spectrum, ATE-N 72 exhibits the absorption due to $\mathrm{C}=\mathrm{O}$ stretching vibration of amide bond at $1660 \mathrm{~cm}^{-1}$, versus ATE exhibits it at $1638 \mathrm{~cm}^{-1}$. Although ATE also indicates absorption due to $\mathrm{N}-\mathrm{H}$ deformation vibration at $1557 \mathrm{~cm}^{-1}$, the absorption of ATE-N 72 cannot be observed. Hino et al. reported that the protonation of Trp derivatives occurs at the 3 -position of indole to generate indolenium cation in acidic conditions, and that cyclization took place owing to the fact that an $\alpha$-nitrogen atom retains enough nucleophilicity to react with the 2-position of the protonated form. ${ }^{27}$ If ATE forms the cyclic structure through treatment with nitric acid, variation of IR spectrum is reasonable. Nitration of aromatic compounds such as indole and pyrrole, which has high electronic density and reactivity, has been reported. ${ }^{28}$ ATE-N 72 indicates strong absorption due to $\mathrm{C}-\mathrm{NO}_{2}$ stretching vibration at $1529 \mathrm{~cm}^{-1}$ and at $1321 \mathrm{~cm}^{-1}$ in IR spectrum. ATE-N 72 is thus introduced nitro group into indole ring by the treatment with nitric acid and seems to change the structure shown in Figure 4.

${ }^{1} \mathrm{H}$ NMR spectrum of ATE-N 72 in $\mathrm{CDCl}_{3}$ is shown in Figure 5 together with that of ATE. The peaks observed in the ${ }^{1} \mathrm{H}$ NMR spectrum of ATE were assigned to as follows.

$\delta 1.2-1.3 \mathrm{CH}_{3}$ of ester $(3 \mathrm{H}), \delta 1.95 \mathrm{CH}_{3}$ of acetyl $(3 \mathrm{H}), \delta 3.3 \mathrm{CH}_{2}$ bonded at the 3 -position of indole $(2 \mathrm{H})$, 

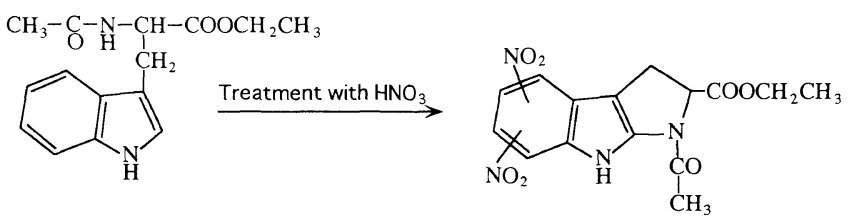

Figure 4. Cyclization of ATE by treatment with nitric acid.
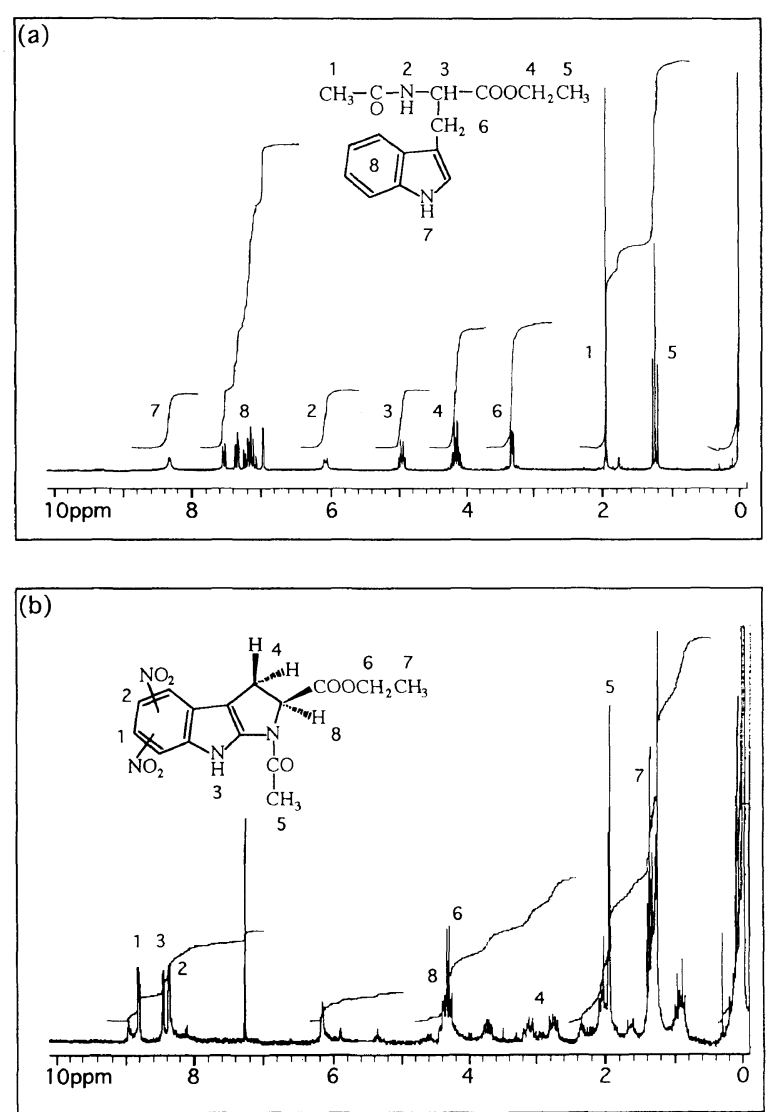

Figure 5. ${ }^{1} \mathrm{H}$ NMR spectra of ATE and ATE-N 72 in $\mathrm{CDCl}_{3}$ : (a) ATE and (b) ATE-N 72.

$\delta 4.1-4.2 \mathrm{CH}_{2}$ of ester $(2 \mathrm{H}), \delta 4.9-5.0 \mathrm{CH}$ of amino acid $(1 \mathrm{H}), \delta 6.0-6.1 \mathrm{NH}$ of amino acid $(1 \mathrm{H}), \delta 6.9-7.6$ indole $(5 \mathrm{H}), \delta 8.35 \mathrm{NH}$ of indole $(1 \mathrm{H})$.

Based on the above, the peaks of ATE-N 72 were assigned to as follows.

$\delta 1.3-1.4 \mathrm{CH}_{3}$ of ester $(3 \mathrm{H}), \delta 1.9-2.0 \mathrm{CH}_{3}$ of acetyl $(3 \mathrm{H}), \delta 4.2-4.3 \mathrm{CH}_{2}$ of ester $(2 \mathrm{H}), \delta 4.4 \mathrm{CH}$ of amino acid $(1 \mathrm{H})$.

In ${ }^{1} \mathrm{H}$ NMR spectrum of ATE-N 72, the peak at $\delta 8.5$ disappeared by addition of $\mathrm{D}_{2} \mathrm{O}$, and was assigned to $\mathrm{NH}$ of indole. In the case of nitration occurred at the indole ring, the electron density of the indole ring is reduced by electron-attractive of nitro group, and the peaks of proton of indole seem to shift to low magnetic field. Two singlet peaks observed at $\delta 8.4$ and at $\delta 8.8$ shifted about $1.5 \mathrm{ppm}$ to low magnetic field compared with that of ATE. Although ATE has five protons in the indole ring, ATE-N 72 exhibits only two singlet peaks in its spectrum. These results support nitration of the indole ring. Split peak at $\delta 2.8-3.1$ was attributed to $\mathrm{CH}_{2}$ bonded at the 3-position of indole through steric difference causes on protons of the $\mathrm{CH}_{2}$ which was taken in a part of the ring structure. The peak at $\delta 6.0$ attributed to $\mathrm{NH}$ of amino acid disappeared by the treatment with<smiles>CCOC(=O)C1CC(NO)c2c1[nH]c1c2CC(C(=O)OCC)N1C(C)=O</smiles><smiles>CC(C[C@H](C)Cl)O[N+](=O)[O-]</smiles><smiles>CCOC(=O)C1Cc2c([nH]c3c2C2CCC3C([N+](=O)[O-])C2)N1C(C)=O</smiles>

Figure 6. Dissociation form of ATE-N 72

nitric acid. This agrees with the results of IR measurement. ATE-N 72 is thus a dinitro compound substituted by nitro groups either at the 5- and 7-positions or at the 4- and 6-positions of the indole ring, and form a cyclic structure as shown in Figure 4.

\section{Coloration Mechanism of ATE-N 72}

ATE-N 72 shows reversible color change in the $\mathrm{pH}$ region of 10.5 to 12.5 , due possibly to a negative charge. From the results of nonaqueous titration using tymol blue as an indicator, ATE-N 72 has negative charge in alkaline $\mathrm{pH}$. Although the lone-pair of nitrogen of indole ring is employed to maintain the aromaticity, the acidity of indole ring of ATE is not so strong as to dissociate negatively. The nitro group introduced into an aromatic ring lowers electronic density of the ring and increases acidity by the strong electronic attractive effect. The nitro group also makes the acidity of aromatic ring increase owing to the distribution of a lone-pair reaches to nitro groups as $p$-nitroaniline and $p$-nitrophenol, and nonlocalized energy becomes large by negative resonance effect. ${ }^{29}$ The acidity of ATE-N 72 appears to increase similarly by introduced nitro group, and ATE-N 72 colored red through the conjugation becomes long by dissociation of indole ring as shown in Figure 6.

The ATE-N 72 thus forms the tricyclic structure which introduced two nitro groups into the indole ring by the treatment with nitric acid. Color change of ATE-N 72 occurs by the dissociation of indole ring, attributable to the strong electron attractive effect of the nitro group.

\section{Color Change of the EGT-N Membrane}

The EGT-N membrane shows a yellow color in acidic $\mathrm{pH}$ and becomes red as well as in ATE treated with nitric acid. Figure 7 shows the $\mathrm{pH}$ dependence of VIS spectra of EGT-N membrane. The membrane was colored yellow below $\mathrm{pH} 10.5$ to absorb the wavelength (around 400 $\mathrm{nm}$ ) that appears bluish-purple to purple, and became red as it absorbed the wavelength (around $500 \mathrm{~nm}$ ) that appears as blue above $\mathrm{pH}$ 12.5. EGT-N shows a color change from yellow to red in the $\mathrm{pH}$ region of 10.5 to 12.5, and this $\mathrm{pH}$ region is similar to that of ATE-N 72 . 


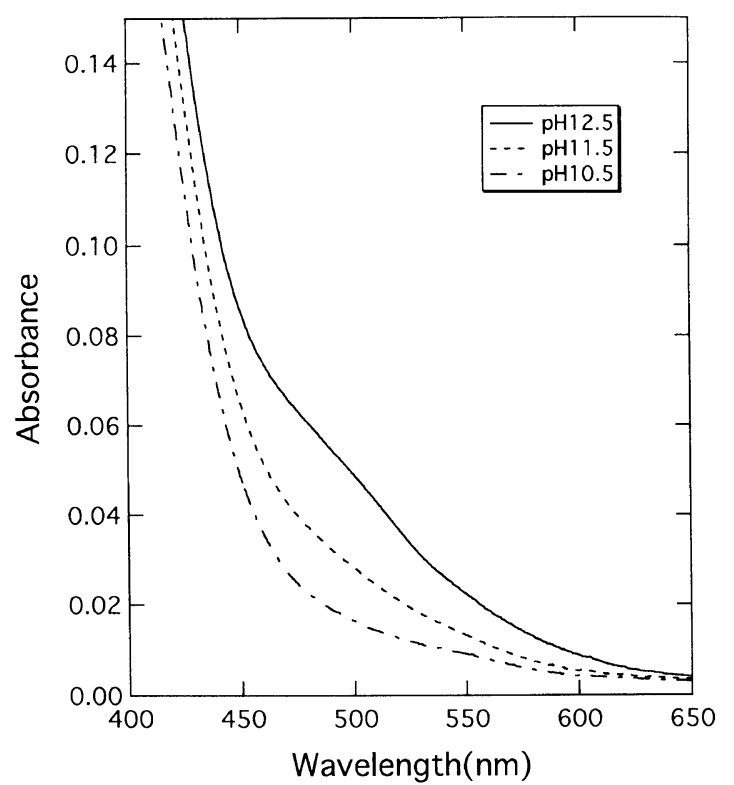

Figure 7. $\mathrm{pH}$ dependence of VIS spectra of EGT-N membrane.

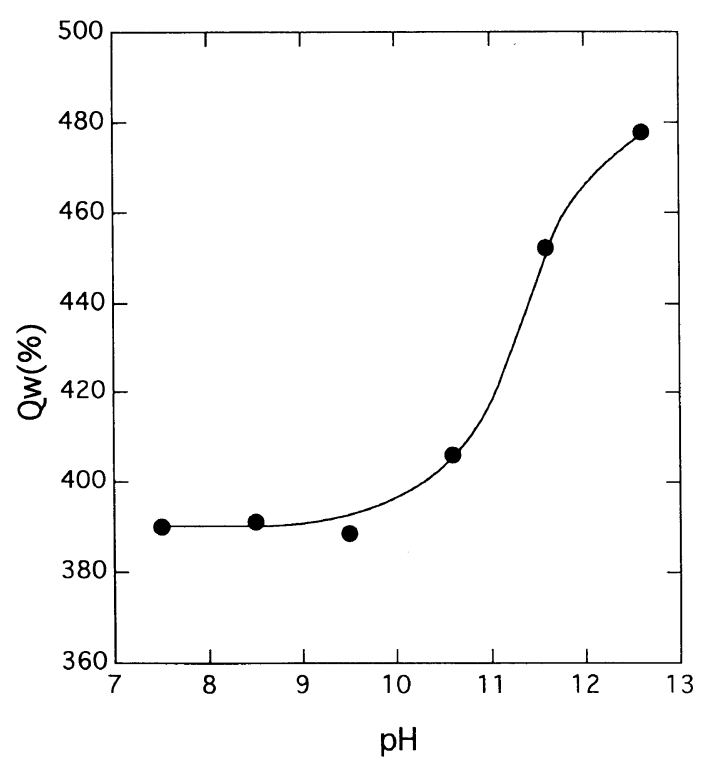

Figure 8. $\mathrm{pH}$ dependence of the degree of swelling $\left(Q_{\mathrm{w}}\right)$ of EGT-N membrane.

\section{Degree of Swelling of the EGT-N Membrane}

The $\mathrm{pH}$ dependence of the degree of swelling $\left(Q_{\mathrm{w}}\right)$ is illustrated in Figure 8. As can be seen from Figure $8, Q_{\mathrm{w}}$ of EGT-N membrane increased above $\mathrm{pH} 10.5$. This $\mathrm{pH}$ region agrees with the $\mathrm{pH}$ region where the change in color of both ATE-N 72 and EGT-N membrane was observed. The variation of $Q_{\mathrm{w}}$ is reversible against $\mathrm{pH}$. Although it is thought about transition of molecular conformation as a reason why the value of $Q_{\mathrm{w}}$ increase against $\mathrm{pH}$, the conformation of EGT-N exists in random conformation in whole $\mathrm{pH}$ region. This exhibits that $Q_{\mathrm{w}}$ increases because the Trp residues within copolypeptide change to the tricyclic structure as well as in the case of ATE treated with nitric acid, and have a negative charge in an alkaline $\mathrm{pH}$.

\section{Solute Permeability of the EGT-N Membrane}

The solute permeability of the EGT-N membrane as well as $Q_{\mathrm{w}}$ varies in the $\mathrm{pH}$ region where color change

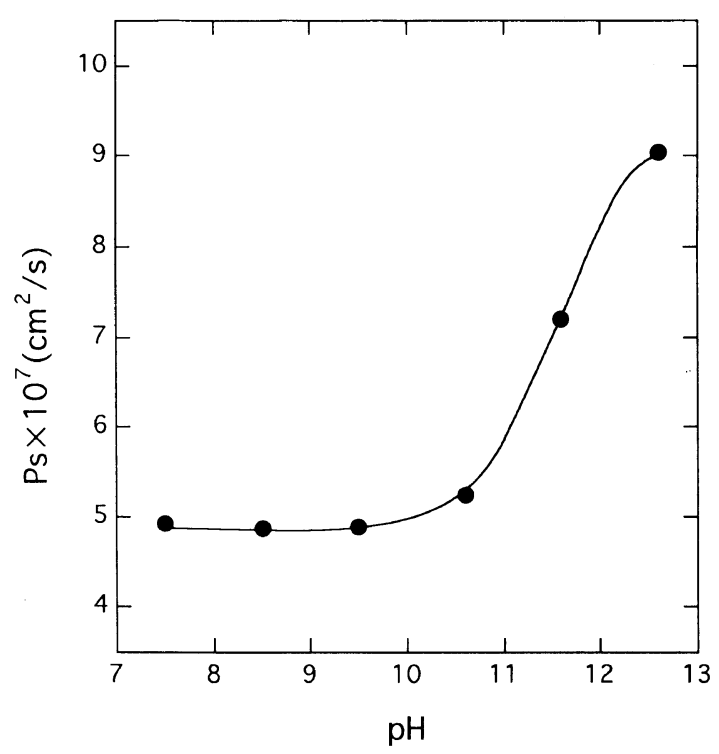

Figure 9. $\mathrm{pH}$ dependence of permeability coefficient of EGT-N membrane.

is observed. Figure 9 shows the $\mathrm{pH}$ dependence of the permeability coefficient $\left(P_{\mathrm{s}}\right)$ of styrene glycol of the membrane. $P_{\mathrm{s}}$ and $Q_{\mathrm{w}}$ increased above $\mathrm{pH} 10.5$. This increment of $P_{\mathrm{s}}$ seems to result from extension of permeation pathway of the membrane by repulsion of dissociating Trp residues. The degree of swelling and solute permeability of EGT-N membrane varied in the region where color change takes place.

Thus, new $\mathrm{pH}$ response hydrogel accompanying color change can be prepared by the treatment with strong acid and is expected to be applicable as material that can monitor interactions of Trp with cationic substances, e.g., drug and metal ions, by color change.

The major conclusions of this investigation are as follows.

(1) $N$-acetyl Trp ethyl ester treated with nitric acid (ATE-N) shows reversible color change from yellow (below $\mathrm{pH} 10.5$ ) to red (above $\mathrm{pH} 12.5$ ).

(2) ATE-N was purified by column chromatography, and the structure of colored compound (ATE-N 72) was identified by ${ }^{1} \mathrm{H}$ NMR and IR measurement.

- ATE-N 72 forms a tricyclic structure by the nucleophilic reaction of $\alpha$-nitrogen atom of ATE and the 2-position of indole ring, and is substituted by nitro group.

- ATE-N 72 is colored yellow by introduction of nitro group, and becomes red owing to the elongation of conjugated system accompanied by dissociation of indole ring above $\mathrm{pH} 10.5$.

(3) The $\mathrm{pH}$ response material, EGT-N, can be prepared by the treatment of copoly $(N$-hydroxyethyl Lglutamine-co-Trp) hydrogel, EGT, with nitric acid.

- EGT-N membrane shows reversible color change as well as in ATE treated with nitric acid, and its physical properties vary drastically in the $\mathrm{pH}$ region where the color change is observed.

- The results of $Q_{\mathrm{w}}$ and $P_{\mathrm{s}}$ reflect the results of ATE-N 72 which dissociates above $\mathrm{pH} 10.5$. 


\section{REFERENCES}

1. P. H. Maurer, J. Immunol., 88, 330 (1962).

2. T. Hayashi, K. Takeshima, Y. Tabata, and A. Nakajima, Polym J., 17, 1148 (1985)

3. Y. Iizuka, K. Wakamatsu, M. Oya, T. Hayashi, M. Iwatsuki, and T. Yamamoto, Kobunshi Ronbunshu, 48, 239 (1991).

4. T. Hayashi, Y. Iizuka, M. Oya, and M. Iwatsuki, Polym. J., 25 , 481 (1993).

5. T. Hayashi, Y. Iizuka, M. Oya, and M. Iwatsuki, Biomaterials, 14, 497 (1993).

6. T. Hayashi, E. Nakanishi, Y. Iizuka, M. Oya, and M. Iwatsuki, Eur. Polym. J., 31, 453 (1995).

7. M. A. Stahman, Ed., "Polyamino Acids, Polypeptides and Proteins," Univ. of Wisconsin Press, Madison, Wisconsin, 1962.

8. J. M. Anderson, K. L. Spilizewski, and A. Hiltner, in "Biocompatibility of Tissue Analogs," D. F. Williams, Ed., CRC Press, Boca Raton, FL, 1985, p 68.

9. S. D. Bruck, Biomater. Med. Artif. Organs, 1, 79 (1973).

10. B. D. Ratner and A. S. Hoffman, in "Hydrogels for Medical and Related Applications," J. D. Andrade, Ed., ACS Symp. No. 31 , American Chemical Society, Washington D.C., 1976, Chapter 1.

11. V. Skarda, F. Rypacek, and M. Ilavsky, J. Bioactive and Compatible Polymers, 8, 24 (1993).

12. D. L. Elbert and J. A. Hubbell, Polymers Annual Review of Materials Science, 26, 365 (1996).

13. E. Nakanishi, E. Sugiyama, S. Hibi, M. Maeda, and T. Hayashi, Polym. J., 23, 983 (1991).

14. E. Nakanishi, K. Hamada, E. Sugiyama, S. Hibi, and T. Hayashi,
Polym. J., 23, 1053 (1991).

15. E. Nakanishi, Y. Shimizu, K. Ogura, S. Hibi, and T. Hayashi, Polym. J., 23, 1061 (1991).

16. D. G. Harvey, E. J. Miller, and W. Robson, J. Chem. Soc., 153 (1941).

17. H. Tauber, J. Am. Chem. Soc., 70, 2615 (1948).

18. J. J. Sharp, A. B. Robinson, and M. D. Kamen, J. Am. Chem. Soc., 95, 6097 (1973)

19. H. Ogawa, T. Sasaki, H. Irie, and H. Tajima, Chem. Pharm. Bull., 26, 3144 (1978).

20. H. Sugimoto, E. Nakanishi, N. Kondo, and S. Hibi, Kobunshi Ronbunshu, 46, 1 (1998).

21. H. Sugimoto, E. Nakanishi, and S. Hibi, Polymer, in press.

22. W. H. Daly and D. Poché, Tetrahedron Lett., 29, 5859 (1988).

23. H. Eckert and B. Foster, Angew. Chem., Int. Ed. Engl., 26, 894 (1987).

24. R. Wilder and S. Mobashery, J. Org. Chem., 57, 2755 (1992).

25. T. Sugie and P. A. Hiltner, J. Macromol. Sci.-Phys., B17, 769 (1980).

26. R. M. Silverstein, G. C. Bassler, and T. C. Morrill, in "Spectrometric Identification of Organic Compounds," John Wiley \& Sons, Inc., New York, N. Y., 1992, p 262.

27. M. Taniguchi and T. Hino, Tetrahedron, 37, 1487 (1981).

28. H. Yamanaka, T. Hino, M. Nakagawa, and T. Sakamoto, in "Heterokan Kagobutu no Kagaku," Kodansha Scientific, Ed., Kodansha Co., Ltd., Tokyo, 1993, p 94.

29. J. B. Hendrickson, D. J. Cram, and G. S. Hammond, in "Organic Chemistry," Y. Yukawa, T. Hanafusa, T. Mukaiyama, and J. Yoshimura, Ed., Hirokawa Publishing Co., Tokyo, 1974, p 299. 